\title{
Rare occurrence of Proteus vulgaris in faeces: a reason for its rare association with urinary tract infections
}

\author{
B. W. SENIOR and D. L. LESLIE
} Department of Medical Microbiology, University of Dundee Medical School, Ninewells Hospital,
Dundee DD1 $9 S Y$

\begin{abstract}
Summary. The faecal carriage rates of different species of Proteeae were assessed in studies with 220 faecal isolates from 219 individuals of whom approximately one-third were well and the remainder had gastro-enteritis. As a result of the development of new media that allowed replacement of the phenylalanine deaminase test with the tryptophan deaminase test and made it possible to combine tests for indole and urease production and for hydrogen sulphide and ornithine decarboxylase formation in two single-tube tests, all strains were speciated with speed, economy and accuracy. Most $(96 \%)$ isolates were either Proteus mirabilis (62\%) or Morganella morgani $(34 \%)$. The significance of these findings in relation to urinary tract infection is discussed. $P$. vulgaris was found in only one $(0.45 \%)$ faecal specimen and this rarity of carriage in faeces is believed to be the main reason for its rare association with urinary tract infections. The frequent association of $M$. morgani, in the absence of other enteropathogenic bacteria, with severe gastroenteritis was noted with interest.
\end{abstract}

\section{Introduction}

Although infections of the urinary tract with strains of Proteus occur less frequently than those with Escherichia coli, they are particularly important in young boys (Bergström, 1972; Hallett et al., 1976) and the elderly (Walkey et al., 1967; Senior, 1979). Furthermore, the consequences of infection with Proteus are often more serious than those with $E$. coli, which is usually confined to the bladder, for Proteus has a special predilection for the upper urinary tract (Fairley et al., 1971; Svanborg Edén et al., 1980) where it may cause damage and death to the renal tubular epithelium (Braude et al., 1960) and the formation of renal stones (Griffith et al., 1973). These events arise through the formation by Proteus species of potent urease isoenzymes (Senior et al., 1980) which cause the degradation of urea and rapidly make the urine alkaline (Senior, 1983).

The common source of urinary tract pathogens is the bowel. Most infections of the urinary tract with Proteus are due to $P$. mirabilis $(96.5 \%)$ and very few to $P$. vulgaris $(1 \cdot 5 \%)$ or Morganella morgani $(P$. morgani) (1.5\%) (Senior, 1979). DNA hybridisation studies (Brenner et al., 1978), urease isoenzyme profiles (Senior et al., 1980) and the sharing of phage (Coetzee, 1963) and bacteriocin receptors

Received 29 Apr. 1985; revised version accepted 17 Jun. 1985.
(Senior and Larsson, 1983) all indicate the close relationship between $P$. mirabilis and $P$. vulgaris. It is remarkable, therefore, that there should be such a wide difference in the frequency with which these organisms are associated with urinary tract infections.

One explanation for the rare association of $P$. vulgaris with infections of the urinary tract might be the fact that analogous bacteriocin production/ sensitivity $(\mathrm{P} / \mathrm{S})$ types to those associated with $P$. mirabilis strains having special affinity for the urinary tract (Senior, 1979) have not yet been found in $P$. vulgaris (unpublished results). Alternatively, there may be a much simpler explanation based on the frequency of occurrence of $P$. vulgaris in the faeces. The aim of this study was to investigate the latter theory through the development of new multicombination biochemical tests which would permit the identification of all species of members of the tribe Proteeae to be made with speed, ease, economy and accuracy.

\section{Materials and methods}

\section{Source and isolation of bacterial strains}

Strains belonging to the tribe Proteeae were isolated from specimens of human faeces submitted to the laboratory for routine investigations. A loopful of each specimen was plated out for single colonies on Desoxycholate 
Citrate Agar (DCA; Oxoid CM35) and also inoculated into Tetrathionate Broth (Oxoid CM29). Both media were incubated overnight at $37^{\circ} \mathrm{C}$. The tetrathionatebroth culture was plated out for single colonies on a DCA plate which was incubated overnight at $37^{\circ} \mathrm{C}$. One nonlactose-fermenting (NLF) colony of every morphological type present on the DCA plates was picked and inoculated into Nutrient Broth (Oxoid CM67). After overnight incubation at $37^{\circ} \mathrm{C}$ a loopful of each broth culture was placed on the surface of a dried tryptophan deaminase agar plate and a loopful seeded into urea/indole medium. After overnight incubation at $37^{\circ} \mathrm{C}$, those cultures that produced tryptophan deaminase were saved and subsequently speciated as detailed below.

\section{Media}

All commercially prepared media were dispensed and sterilised according to the manufacturer's instructions. Each batch of every medium was tested with appropriate positive and negative control test organisms before being used in the study. Tryptophan deaminase agar medium (TDA) contained bacteriological peptone (Oxoid L37) 30 g, Lab-Lemco powder (Oxoid L29) $50 \mathrm{~g}$, L-tryptophan (Sigma) $10 \mathrm{~g}$, Agar No. 3 (Oxoid L13) $12 \mathrm{~g}$, bile salts (Oxoid L55) $3 \mathrm{~g}$ and yeast extract (Oxoid L21) $3 \mathrm{~g}$ dissolved in distilled water to a volume of $1 \mathrm{~L}$. The medium was sterilised by autoclaving at $121^{\circ} \mathrm{C}$ for $15 \mathrm{~min}$ and, when cool, poured into petri dishes. Urea/indole medium was prepared by supplementing $95 \mathrm{ml}$ of sterile Tryptone Water (Oxoid CM87) with $5 \mathrm{ml}$ of a Seitzfiltered refrigerated stock solution of urea $40 \mathrm{~g}$, phenolphthalein $(1 \% \mathrm{w} / \mathrm{v}$ in propan-2-ol) $10 \mathrm{ml}$ made up to $100 \mathrm{ml}$ with distilled water. The medium was dispensed into sterile, cotton wool-plugged tubes. Ornithine decarboxylase/sulphide medium contained Tryptone Water (Oxoid CM87) $0.5 \mathrm{~g}$, L-ornithine hydrochloride (Sigma) $1 \mathrm{~g}$, ferrous ammonium sulphate $20 \mathrm{mg}$, sodium thiosulphate $20 \mathrm{mg}$ and a little bromocresol purple dye, dissolved in distilled water to $100 \mathrm{ml}$. After autoclaving at $121^{\circ} \mathrm{C}$ for $15 \mathrm{~min}$, the medium was allowed to cool and then supplemented with glucose to a final concentration of $0.1 \% \mathrm{w} / \mathrm{v}$ from a Seitz-filtered glucose $10 \% \mathrm{w} / \mathrm{v}$ in water stock solution. The medium was dispensed aseptically into bijoux bottles. Triple sugar agar medium was prepared by supplementing sterile molten, cool Lab-Lemco Agar (Oxoid CM17) containing neutral red with lactose, maltose and inositol, each to a concentration of $1 \% \mathrm{w} / \mathrm{v}$ from Seitz-filtered $10 \% \mathrm{w} / \mathrm{v}$ stock solutions of each sugar in water. After gentle mixing, the medium was poured into petri dishes. Peptone water sugars were made by supplementing Peptone Water (Oxoid CM9) with a little bromocresol purple dye and the sugar to a final concentration of $1 \% \mathrm{w} / \mathrm{v}$. The medium was dispensed into tubes or bijoux bottles and sterilised by steaming for $30 \mathrm{~min}$ on each of three successive days.

\section{Speciation of strains}

The formation of tryptophan deaminase was indicated by the formation of a stable brown pigment around strains growing on TDA plates. Ornithine decarboxylase/ sulphide medium and triple sugar medium were seeded from broth cultures of all strains that formed tryptophan deaminase. Those strains which failed to produce urease as indicated by an inability to turn the $p \mathrm{H}$ indicator in the urea/indole medium to pink were, in addition, inoculated from their broth cultures into glucose, galactose, and trehalose peptone-water sugars. All inoculated media were incubated overnight at $37^{\circ} \mathrm{C}$. Ehrlich's reagent was gently added to the cultures in the urea/indole medium. Indole formation was indicated by the reagent turning red. Ornithine decarboxylase formation was indicated by the development of alkalinity. Hydrogen sulphide production was revealed by the formation of a black deposit. If any isolate formed acid on the triple sugar agar medium, four tubes of single sugar peptone waters (lactose, maltose, inositol and adonitol) were inoculated from its broth culture, incubated overnight at $37 \mathrm{C}$ and the reactions to the individual sugars recorded. The species of each isolate was determined by reference to table I.

\section{Results}

During a 6-month period, 220 strains belonging to species of the tribe Proteeae were isolated from the faeces of 219 people of whom $120(55 \%)$ were female, $94(43 \%)$ male, and five $(2 \%)$ of unstated sex; $70 \%$ of the females and $60 \%$ of the males were in hospital. Clinical information was given about 202 of the individuals and of these, $148(73 \%)$ had symptoms of gastro-enteritis in the form of diarrhoea only $(72 \%$ of cases) or diarrhoea and vomiting ( $23 \%$ of cases) or vomiting only ( $5 \%$ of cases). None was receiving antibiotics when faecal samples were collected. The remaining 71 people $(32 \%$ of the total) were either healthy, or unwell with undisclosed illness. Known intestinal pathogenic bacteria were found in only $20(9 \%)$ of the specimens of faeces and these and their association with species of Proteeae are presented in table II.

Speciation of the 220 strains of Protecae isolated showed that $136(61.8 \%)$ were $P$. mirabilis, 74 $(33.6 \%)$ were $M$. morgani, four $(1.8 \%)$ were Providencia alcalifaciens, three $(1.36 \%)$ were Prot. rettgeri, two $(0.9 \%)$ were Prov stuarti and one $(0.45 \%)$ was P. vulgaris. There were no isolations of Tatumella ptyseos (Hollis et al., 1981) or Prov. rustigiani (Hickman-Brenner et al., 1983) or P. penneri (Hickman et al., 1982).

An analysis of the frequency of isolation of the different species of Proteecte from the faeces of patients of different age and sex is presented in table III. P. mirabilis and M. morgani were isolated from patients in every 10-year age group from infancy to old age. Generally P. mirabilis was isolated a little 
Table I. The biochemical reactions of members of the tribe Proteeae and Tatumella ptyseos

\begin{tabular}{|c|c|c|c|c|c|c|c|c|c|c|c|c|}
\hline \multirow[b]{3}{*}{ Organism } & \multicolumn{12}{|c|}{ Biochemical test and result* } \\
\hline & \multirow{2}{*}{\multicolumn{2}{|c|}{ 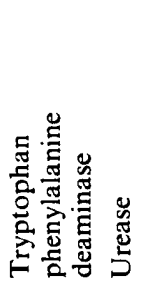 }} & \multirow[b]{2}{*}{ 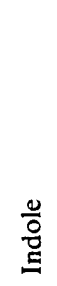 } & \multirow[b]{2}{*}{ 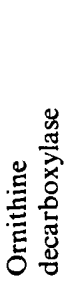 } & \multirow[b]{2}{*}{$\stackrel{I}{I}$} & \multicolumn{6}{|c|}{ Acid from } & \multirow[b]{2}{*}{ 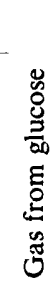 } \\
\hline & & & & & & 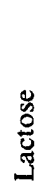 & $\begin{array}{l}\mathscr{\delta} \\
\stackrel{0}{\Xi} \\
\sum_{\Sigma}^{\pi}\end{array}$ & $\begin{array}{l}\stackrel{\overrightarrow{0}}{\bar{\delta}} \\
\stackrel{\Xi}{0}\end{array}$ & $\begin{array}{l}\overrightarrow{0} \\
\stackrel{\mathscr{Z}}{0} \\
\stackrel{0}{\alpha}\end{array}$ & 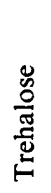 & 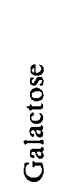 & \\
\hline Proteus mirabilis & + & $(+)$ & - & + & $(+)$ & - & - & - & - & + & NT & $(+)$ \\
\hline$\dagger$ Proteus penneri & + & + & - & - & $\mathrm{V}$ & - & + & - & - & + & + & $\mathrm{V}^{\prime}$ \\
\hline Proteus vulgaris & + & + & + & - & $(+)$ & - & - & - & - & V & NT & $(+)$ \\
\hline Morganella morgani & + & + & + & $(+)$ & - & - & - & - & - & V & NT & $(+)$ \\
\hline Providencia rettgeri & + & + & + & - & - & - & - & + & + & - & + & $(-)$ \\
\hline Providencia stuarti & + & V & + & - & - & - & - & {$[+]$} & {$[-]$} & + & + & - \\
\hline Providencia alcalifaciens & + & - & + & - & - & - & - & - & + & - & - & V \\
\hline$\ddagger$ Providencia rustigiani & + & - & $(+)$ & - & - & - & - & - & - & - & + & V \\
\hline$\S$ Tatumella ptyseos & + & - & - & - & - & - & - & - & - & + & + & - \\
\hline
\end{tabular}

${ }^{*}+=$ Production; $-=$ no production; ()$=$ most strains; $\mathrm{V}=$ different strains give different results; NT $=$ not tested.

$\dagger$ Data from Hickman et al., 1982.

$\ddagger$ Data from Hickmann-Brenner et al., 1983.

$\S$ Data from Hollis et al., 1981 .

Table II. The 20 enteropathogenic isolates* and their association with species of the tribe Proteeae

\begin{tabular}{|c|c|c|c|c|c|}
\hline \multirow[b]{3}{*}{$\begin{array}{l}\text { Enteropathogenic } \\
\text { organism }\end{array}$} & \multicolumn{5}{|c|}{ Number of isolations of pathogen } \\
\hline & \multirow[b]{2}{*}{ Total } & \multicolumn{4}{|c|}{ in association with } \\
\hline & & 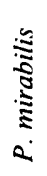 & $\begin{array}{l}\tilde{3} \\
\mathbf{8} \\
\vdots \\
\mathbf{2} \\
\mathbf{\Sigma}\end{array}$ & 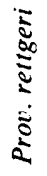 & $\begin{array}{l}0 \\
5 \\
5 \\
\vdots \\
0 \\
0\end{array}$ \\
\hline Salmonella sp. & 10 & 5 & 4 & 1 & 0 \\
\hline Shigella sp. & 3 & 0 & 2 & 0 & 1 \\
\hline Campylobacter sp. & 3 & 1 & 2 & 0 & 0 \\
\hline Clostridium difficile & 3 & 2 & 0 & 1 & 0 \\
\hline Non-cholera vibrio & 1 & 0 & 1 & 0 & 0 \\
\hline
\end{tabular}

* The 20 enteropathogenic isolates were from 219 faecal specimens examined (see text).

more frequently than $M$. morgani regardless of the age or sex of the patient. From elderly women, $P$. mirabilis isolates greatly outnumbered $M$. morgani isolates, but the reverse situation was found in males of $11-30$ and $41-50$ years.

An analysis of the data with regard to clinical symptoms showed that of the 71 patients with no symptoms of gastro-enteritis, $44(62 \%)$ were infected with $P$. mirabilis and $27(38 \%)$ with $M$. morgani. A similar ratio between $P$. mirabilis and M. morgani was found among the 107 patients with diarrhoea alone, of whom $69 \%$ were infected with $P$. mirabilis and $30 \%$ with $M$. morgani, but a different ratio was found for the 34 patients with both 
Table III. Frequency of isolation of species of Proteeae from faeces of patients according to age and sex

\begin{tabular}{|c|c|c|c|c|c|c|c|c|c|c|c|c|c|c|}
\hline \multirow[b]{3}{*}{$\begin{array}{l}\text { Age } \\
\text { group } \\
\text { (years) }\end{array}$} & \multicolumn{14}{|c|}{ Number of strains of the stated species } \\
\hline & \multicolumn{7}{|c|}{ from male patients } & \multicolumn{7}{|c|}{ from female patients } \\
\hline & $\begin{array}{c}\text { Number of } \\
\text { patients }\end{array}$ & 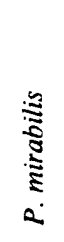 & $\begin{array}{l}\tilde{\Xi} \\
\mathbf{5} \\
\vdots \\
\Xi \\
\Sigma\end{array}$ & 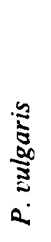 & 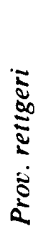 & 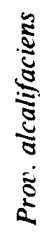 & 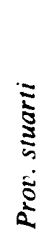 & $\begin{array}{c}\text { Number of } \\
\text { patients }\end{array}$ & 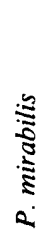 & $\begin{array}{l}\tilde{\Xi} \\
\mathbf{5} \\
\vdots \\
\Sigma \\
\Sigma \\
\Sigma\end{array}$ & 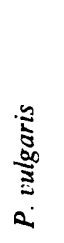 & 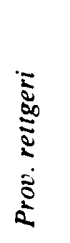 & 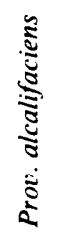 & 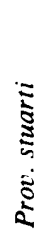 \\
\hline $0-10$ & 44 & 27 & 17 & 0 & 0 & 0 & 0 & 36 & 23 & 11 & 0 & 1 & 1 & 0 \\
\hline $11-20$ & 2 & 0 & 2 & 0 & 0 & 0 & 0 & 9 & 5 & 3 & 1 & 0 & 0 & 0 \\
\hline 2130 & 9 & 1 & 8 & 0 & 0 & 0 & 0 & 11 & 5 & 6 & 0 & 0 & 0 & 0 \\
\hline $31-40$ & 6 & 4 & 2 & 0 & $\mathbf{0}$ & 0 & 0 & 3 & 3 & 0 & 0 & 0 & 0 & 0 \\
\hline $41-50$ & 5 & 1 & 4 & 0 & 0 & 0 & 0 & 9 & 5 & 2 & 0 & 0 & 2 & 0 \\
\hline $5 \mid-60$ & 4 & 2 & 1 & 0 & 0 & 1 & 0 & 3 & 2 & 1 & 0 & 0 & 0 & 0 \\
\hline $6 \mathrm{I}-70$ & 2 & 2 & 0 & 0 & 0 & 0 & 0 & 9* & 7 & 2 & 0 & 0 & 0 & 1 \\
\hline $71-80$ & 7 & 4 & 2 & 0 & 0 & 0 & 1 & 15 & 13 & 1 & 0 & 1 & 0 & 0 \\
\hline $81+$ & 6 & 5 & 1 & 0 & 0 & 0 & 0 & 19 & 15 & 4 & 0 & 0 & 0 & 0 \\
\hline Unknown & 9 & 4 & 4 & 0 & 1 & 0 & 0 & 6 & 5 & 1 & 0 & 0 & 0 & 0 \\
\hline Total & 94 & 50 & 41 & 0 & I & 1 & 1 & 120 & 83 & 31 & 1 & 2 & 3 & 1 \\
\hline $\begin{array}{l}\text { Percentage } \\
\text { of total }\end{array}$ & 100 & 53 & 44 & 0 & 1 & 1 & 1 & 100 & 70 & 26 & 0.8 & 1.6 & $2 \cdot 4$ & 0 . \\
\hline
\end{tabular}

There were 5 patients of unstated age and sex of whom 3 yielded $P$. mirabilis and 2 yielded $M$. morgani.

* One patient carried 2 different species.

diarrhoea and vomiting among whom $50 \%$ were infected with $P$. mirabilis and $47 \%$ with $M$. morgani.

\section{Discussion}

This study sought the development of new media to permit the biochemical speciation of all representatives of the tribe Proteeae with speed, economy of media and the minimum of manipulations in order that the degree of correlation between frequency of faecal carriage of the different species and their frequency in urinary tract infection might be assessed.

The new media that we developed proved reliable and are believed to be accurate; with very few exceptions, each strain gave results that were typical and fully in agreement with only one of the different species of the tribe Proteeae. The exceptions included a small number of $\mathrm{H}_{2} \mathrm{~S}$-negative variants of $P$. mirabilis and $P$. vulgaris, well within the frequency range observed by others (Brenner et al, 1978), and one strain of the ornithine decarboxylase-negative biotype of $M$. morgani which others have described (Hickman et al., 1980).
Strains belonging to the tribe Proteeae are easily recognised for, with the exception of strains of Tatumella ptyseos (Hollis et al., 1981), they are unique among the Enterobacteriaceae in possessing the ability to deaminate amino acids oxidatively. The test for this ability has usually been performed with phenylalanine, the deaminated product phenyl pyruvic acid forming a transient green colour upon addition of ferric chloride (Henriksen and Closs, 1938; Henriksen, 1950). Polster and Svobodova (1964) advocated the use of tryptophan instead of phenylalanine and reported that only strains of the tribe Proteeae formed a red-brown diffusible pigment (presumably indole-3-pyruvic acid) when growing on media containing tryptophan. Using their medium, we found, as they did, that a small number of $M$. morgani strains failed to produce pigment. The modified medium we devised supported a better growth of $M$. morgani and all strains of Proteeae produced pigment. All non-pigmentforming strains were also phenylalanine deaminase negative (data not shown). The inclusion of bile salts appeared to have no effect on pigment production but, by preventing swarming, permitted about 
12 strains to be tested together on one plate. The brown pigment, in contrast to the green pigment from phenylalanine, did not fade nor did it require the addition of ferric chloride to show its presence. Because of these factors and the ease, reliability and reproducibility of the test, we recommend the use of our modified tryptophan deaminase medium in preference to the phenylalanine test.

The urea/indole medium proved helpful in that it permitted rapid recognition, with high probability, of the commonest species of Proteeae, P. mirabilis (urease positive, indole negative), in a single tube test. Phenolphthalein was selected as $p \mathrm{H}$ indicator instead of the more commonly used indicator phenol red because it changed from colourless to pink at a much higher $p \mathrm{H}$ than the latter, thereby avoiding possible confusion between weak urease producers, e.g. strains of Enterobacter, Serratia and Pseudomonas species, and the strong urease producers of the Proteeae. The tryptone water was sufficiently buffered and rich to permit good growth and tryptophan breakdown before high alkalinity prevented this. There was never any difficulty in reading both urease positive and indole positive reactions because one was pink and the other red and the acid of the Ehrlich's reagent caused a yellow band to appear between each colour.

Detection of hydrogen sulphide formation is often not very reliable but the ornithine decarboxylase/sulphide medium we devised was always satisfactory and most useful in that the reactions in this one medium when considered with the indole/urea result could distinguish four different species- $P$. mirabilis, $P$. vulgaris, $M$. morgani and Prov. rettgeri.

In our experience, strains of $P$. mirabilis and $M$.

\section{REFERENCES}

Bergström T 1972 Sex differences in childhood urinary tract infection. Archives of Diseases of Childhood 47:227-232.

Braude A I, Siemienski J, Shapiro A B 1960 The role of bacterial urease in the pathogenesis of pyelonephritis. In: Quinn E L, Kass E H (eds) Biology of pyelonephritis, Churchill Livingstone, London, pp 69-88.

Brenner D J et al. 1978 Deoxyribonucleic acid relatedness of Proteus and Providencia species. International Journal of Systematic Bacteriology 28:269-282.

Coetzee J N 1963 Lysogeny in Proteus rettgeri and the host-range of $P$. rettgeri and $P$. hauseri bacteriophages. Journal of General Microbiology 31:219-229.

Fairley K F et al. 1971 Site of infection in acute urinary tract infection in general practice. Lancet 2:615-618.

Griffith D P, Musher D M, Campbell J W 1973 Inhibition of bacterial urease. Investigative Urology 11:234-238.

Hallett R J, Pead L, Maskell R 1976 Urinary infection in boys. A three year prospective study. Lancet 2:1107-1110.

Henriksen SD 1950 A comparison of the phenylpyruvic acid morgani are more frequently encountered than $P$. vulgaris and Providencia species and with this in mind our triple sugar medium fulfilled two useful functions. If strains did not show acid formation on it they were pure isolates of either $P$. mirabilis or $M$. morgani and free from lactose-fermenting contaminants. Whenever a strain formed acid on the medium this indicated that the isolate was either a lactose-fermenting contaminant or a strain of the more rarely encountered $P$. vulgaris, $P$. penneri or a species of Providencia, and this was readily resolved to species level by subculture in the four single-sugar tubes.

The most commonly isolated species of Proteeae from faeces was $P$. mirabilis and this would explain its frequent association with urinary tract infections (Senior, 1979). M. morgani was also common and found in about one third of faecal specimens irrespective of the age and sex of the patient. Its rare association with urinary tract infections (Senior, 1979) has been attributed to its relatively slow growth rate in urine and its inability to make urine rapidly alkaline despite its potent urease enzyme (Senior, 1983). The results showed unequivocally that $P$. vulgaris, in spite of its name (vulgaris $=$ common), was rarely found in human faeces and this is therefore the most probable reason for its rare association with urinary tract infections (Senior, 1979).

It was noted with interest that, in the absence of other known enteropathogenic bacteria or antibiotic therapy, $M$. morgani was associated with diarrhoea and vomiting at a higher frequency than expected. We hope to investigate whether such strains can produce enterotoxins.

reaction and the urease test in the differentiation of Proteus from other enteric organisms. Journal of Bacteriology 60:225-231.

Henriksen S D, Closs K 1938 The production of phenylpyruvic acid by bacteria. Acta Pathologica et Microbiologica Scandinavica 15:101-113.

Hickman-Brenner F W, Farmer J J, Steigerwalt A G, Brenner D J 1983 Providencia rustigianii: a new species in the family Enterobacteriaceae formerly known as Providencia alcalifaciens biogroup 3. Journal of Clinical Microbiology 17:10571060.

Hickman F W, Farmer J J, Steigerwalt A G, Brenner D J 1980 Unusual groups of Morganella ("Proteus") morganii isolated from clinical specimens, lysine-positive and ornithinenegative biogroups. Journal of Clinical Microbiology 12:8894.

Hickman F W, Steigerwalt A G, Farmer J J, Brenner D J 1982 Identification of Proteus pennerisp. nov. formerly known as Proteus vulgaris indole negative or as Proteus vulgaris biogroup 1. Journal of Clinical Microbiology 15:1097-1102.

Hollis D G, Hickman F W, Fanning G R, Farmer J J, Weaver R 
E. Brenner D J 1981 Tatumella ptyseos gen. nov., sp. nov., a member of the family Enterobacteriaceae found in clinical specimens. Journal of Clinical Microbiology 14:79-88.

Polster M, Svobodova M 1964 Production of reddish-brown pigment from DL-tryptophan by enterobacteria of the Proteus-Providencia group. Experientia 20:637-638.

Senior B W 1979 The special affinity of particular types of Proteus mirabilis for the urinary tract. Journal of Medical Microbiology 12:1-8.

Senior B W 1983 Proteus morgani is less frequently associated with urinary tract infections than Proteus mirabilis-an explanation. Journal of Medical Microbiology 16:317-322.

Senior B W, Bradford N C, Simpson D S 1980 The ureases of
Proteus strains in relation to virulence for the urinary tract. Journal of Medical Microbiology 13:507-512.

Senior B W, Larsson P 1983 A highly discriminatory multityping scheme for Proteus mirabilis and Proteus vulgaris. Journal of Medical Microbiology 16: 193-202.

Svanborg Edén C, Larsson P, Lomberg H 1980 Attachment of Proteus mirabilis to human urinary sediment epithelial cells in vitro is different from that of Escherichia coli. Infection and Immunity 27:804-807.

Walkey F A, Judge T G, Thompson J, Sarkari N B 1967 Incidence of urinary infection in the elderly. Scottish Medical Journal 12:411-414. 